\title{
CÁDIZ Y EL COMERCIO MARÍTIMO GENOVÉS EN EL SIGLO XIV ${ }^{1}$
}

\author{
DANiel Ríos TOLEDANO ${ }^{2}$ \\ Universidad de Cádiz
}

Recibido: 13 de abril de 2018

Aceptado: 4 de mayo de 2018

\begin{abstract}
Resumen
El presente artículo tiene como objetivo principal abordar el papel desempeñado por el puerto de Cádiz como escala esencial para las embarcaciones genovesas que surcaban la ruta atlántica desde el año 1277. A partir del análisis de las actas notariales genovesas recopiladas por Renée Doehaerd y Léone Liagre de Sturler, se pretende reconstruir la actividad mercantil del puerto marítimo de Cádiz en el comercio internacional durante el siglo XIV. Nuestra atención se centrará en cuestiones estrechamente relacionadas con la navegación y las actividades comerciales, tales como las rutas, las mercancías, los pilotos, los seguros marítimos, el tipo de embarcación, entre otros asuntos.
\end{abstract}

\section{Palabras clave}

Génova; Comercio; Cádiz; Castilla; Redes portuarias.

\begin{abstract}
This article has as a main aim to address the role played by the port of Cadiz as a crucial stopover for Genoese ships which sailed the Atlantic route since 1277. On the basis of a detailed analysis of Genoese notarial acts compiled by Renée Doehaerd and Léone Liagre de Sturler, we try to reconstruct the commercial activity within international trade of the seaport of Cádiz over the fourteenth century. Our attention focuses on issues closely related to navigation and commercial operations, such as routes, merchandise, pilots, maritime insurances, ship types, among others.
\end{abstract}

\section{Keyword}

Genoa; Trade; Cadiz; Castile; Port networks.

\section{Resumé}

Dans cet article, on se propose d'aborder le rôle primordial qu'a joué le port de Cadix en tant qu'escale indispensable pour les embarcations génoises qui sillonnaient la route atlantique depuis l'année 1277. À partir de l'analyse des actes notariés génois recueillis par Renée Doehaerd et Léone Liagre de Sturler, on tentera de reconstruire l'activité mercantile du port maritime de Cadix dans le contexte

\footnotetext{
1 Mis mayores agradecimientos al profesor Raúl González Arévalo y al profesor Rafael Sánchez Saus por sus sugerencias y anotaciones inestimables.

2 Correo electrónico: daniel.riostoledano@alum.uca.es. ORCID: https://orcid.org/0000-0001-5633-944X.
} 
du commerce international tout au long du XIVe siècle. Notre attention se focalisera sur les questions qui présentent un lien étroit avec la navigation et les activités commerciales, telles que les routes, les marchandises, les pilotes, les assurances maritimes, le type d'embarcation.

Mots clefs

Gênes; Commerce; Cadix; Castille; Réseau portuaire.

«Viejos y tardos ya nos encontrábamos, al arribar a aquella boca estrecha donde Hércules plantara sus columnas, para que el hombre más allá no fuera...» Dante Alighieri, Divina Comedia (Infierno, XXVI)

\section{Introducción}

El 23 de septiembre de 1357 se reunió en Pera la compañía mercantil formada por los genoveses Nicolò Gentile, Oberto di Moneglia, Ambrogio Tranerio, Odoardo de Mari y Dorino de Paravagna, burgués de Pera. La sociedad disponía de un capital de 35.400 perperis de oro que fue invertido en la adquisición de 7.600 cántaros de alumbre de Focea. Durante la reunión se acordó que el mercader Nicolò Gentile, en caso de que adquiriera dicho alumbre, se encargaría de venderlo in Cadese vel Sibilia vel Lisbonis vel in aliqua parte citra Frandriam ${ }^{3}$. Este ejemplo permite reafirmar el potente interés de los mercaderes genoveses por el área comercial de la Europa atlántica y, además, permite considerar a la ciudad de Cádiz como centro de operaciones mercantiles de primer orden para Génova.

A pesar de que numerosos autores hayan hecho referencia a su actividad portuaria durante la Baja Edad Media ${ }^{4}$, resulta insólito el hecho de que, entre las principales ciudades del Reino de Sevilla, Cádiz, concretamente su puerto más notable, no cuente con un estudio exhaustivo que analice las características más significativas de su actividad marítimacomercial $^{5}$. Bien es cierto que esta relegación historiográfica es fruto de la pérdida de la

\footnotetext{
Liagre de Sturler (ed.), Les relations commerciales entre Gênes, la Belgique et l'Outremont, d'après les archives notariales génoises, 1320-1400, 2 vols., doc. 294.

4 Sin ánimo de ser exhaustivos: Ladero Quesada, "Unas cuentas en Cádiz (1485-1486)", pp. 87-120. Rumeu de Armas, Cádiz, metrópoli del comercio con África en los siglos XV y XVI. Sánchez Herrero, Cádiz. La ciudad medieval y cristiana (1260-1525). López GarRIDO, El Privilegio Rodado de los Reyes Católicos a Cádiz en 1493. Aznar Vallejo, "Cádiz y su región en la expansión atlántica", pp. 11-23. Bello León, "El Reino de Sevilla en el comercio exterior castellano (siglos XIV-XV)", pp. 57-80. OtтE, Sevilla y sus mercaderes a fines de la Edad Media. Sánchez Saus, "Cádiz en la época medieval", pp. 146-281. Aznar VAllejo, "Andalucía y el Atlántico Norte a fines de la Edad Media", pp. 103-120. D’ARIEnzo, "Le relazioni tra Genova e Cadice fra il XIII e il XV secolo", pp. 733-745. GonZÁLez JimÉneZ, "Cádiz en el siglo XIII: Historia de un proyecto frustrado", pp. 747-758. Collantes de Terán SÁnchez, "Papel del Atlántico en la configuración de Andalucía", pp. 85-105. GonZÁLeZ ZaLACAIN, "De puerto a puerto: las relaciones entre los puertos de la Bahía de Cádiz (Siglos XV-XVI)", pp. 147-177.

5 En 1951, Roberto S. Lopez cuando estudió la presencia de mallorquines y genoveses en la ruta atlántica en el siglo XIII, afirmó que Cádiz "was visited by many Genoese merchants, but there is no monograph
} 
documentación local de época bajomedieval. Esta ausencia documental ha obligado a los historiadores a realizar un valioso esfuerzo historiográfico con el fin de reconstruir la realidad histórica de la ciudad de Cádiz en época medieval.

Ante tal circunstancia, resulta de vital importancia recurrir a los archivos extranjeros para cubrir las lagunas documentales castellanas 6 . En este sentido, las fuentes italianas se han revelado como un recurso idóneo para abordar los puertos atlánticos andaluces, tal como han manifestado las investigaciones realizadas por Raúl González Arévalo ${ }^{7}$. Es una metodología que está aportando interesantes resultados, como han puesto de relieve las publicaciones realizadas por Adela Fábregas para el Reino de Granada ${ }^{8}$ o por David Igual para el caso del puerto de Valencia ${ }^{9}$. Es, indiscutiblemente, un procedimiento que debe ser aplicado en profundidad para el caso de los puertos de la Andalucía atlántica. El objetivo de este trabajo es profundizar en el papel que desempeñó Cádiz como escala para las embarcaciones genovesas que surcaban la ruta atlántica a partir de 1277. El marco cronológico se centrará en el siglo XIV, período definido por la historiografía como una «época de crisis». No obstante, prevalecerán las décadas comprendidas entre 1340-1400. Entre otros motivos, por un lado, desde una perspectiva bélica, la Guerra del Estrecho tuvo una incidencia perjudicial en el desarrollo de los intercambios comer-ciales entre el Mediterráneo y el Atlántico y, por otro lado, durante la segunda mitad del siglo XIV se produjo la consolidación definitiva de la ruta de Poniente.

on its trade in the Middle Ages". Ha llovido mucho desde entonces, pero aún seguimos careciendo de un estudio exhaustivo sobre la navegación y el comercio en el puerto de Cádiz en época medieval. Lopez, "Majorcans and Genoese on the North Sea Route in the Thirteenth Century", p. 1.166.

6 Recientemente, Michel Bochaca y Enrique Ruiz han analizado la actividad comercial de los mercaderes bretones en la Andalucía atlántica conjugando la documentación bretona y andaluza: Ruzz Pilares y Bоснаса, "Un exemple de relations commerciales entre le pays de Léon et l'Andalousie au début du XVI siècle, d'après le compte d'un marchand de Morlaix", pp. 7-34. Agradezco a mi amigo y colega Enrique Ruiz que me facilitara el citado texto.

7 GonZÁlez Arévalo, "La costa del Reino de Sevilla en la documentación náutica italiana (siglo XV)", pp. 301-317; "Comercio exterior del Reino de Sevilla a través de los manuales de mercaderías italianos bajomedievales", pp. 221-255; "Corso, comercio y navegación en el siglo XV: Castilla y las galeras mercantiles de Florencia”, pp. 61-95; "Florentinos entre Cádiz y Sevilla en los siglos XIV y XV”, pp. 273-307; “Acordes y desacuerdos. Navegación y comercio de las galeras mercantiles de Venecia y Florencia en el Mediterráneo ibérico desde una perspectiva comparada", pp. 145-191; "En el Mediterráneo atlántico: Andalucía y las marinas italianas en la ruta de Poniente (siglo XV)", en prensa. Agradezco al profesor González Arévalo que me permitiera la consulta del texto inédito.

8 Fábregas García, Producción y comercio de azúcar en el Mediterráneo medieval. El ejemplo del Reino de Granada; "Redes de comercio y articulación portuaria del Reino de Granada: puertos y escalas en el tráfico marítimo bajomedieval", pp. 69-102; "La integración del reino nazarí de Granada en el espacio comercial europeo (siglos XIII-XV)", pp. 11-40; "Acercamiento y acuerdos comerciales entre Granada y Venecia al filo de 1400", pp. 643-664; "El reino nazarí de Granada como área de comercio internacional: ¿Colonia mercantil o espacio de integración?”, pp. 153-169; "Il regno nasride di Granada e i mercanti del Mezzogiorno italiano", pp. 333-349.

9 Igual Luis, "Valencia y Sevilla en el sistema económico genovés de finales del siglo XV", pp. 79-116; "Las galeras mercantiles venecianas y el puerto de Valencia, 1391-1534", pp. 179-200; Valencia e Italia en el siglo XV: rutas, mercados y hombres de negocios en el espacio económico del Mediterráneo occidental. 
Las fuentes disponibles para realizar este estudio proceden de las actas notariales genovesas correspondientes al siglo XIV, que fueron recopiladas en las publicaciones de Renée Doehaerd ${ }^{10}$ y Léone Liagre de Sturler ${ }^{11}$. El principal óbice de estas fuentes es la limitación geográfica: ambos autores se centraron en recoger exclusivamente los protocolos notariales referentes a los intercambios entre Génova y Flandes, obviando numerosos registros sobre el comercio genovés con la Península Ibérica, como bien señaló Yves Renouard ${ }^{12}$. En estos protocolos notariales se conservan, principalmente, contratos de fletamento y pólizas de seguro que habían contratado los mercaderes ligures. En ambos casos, aportan una información realmente valiosa sobre los viajes: mercancías, patrones, seguros marítimos, mercaderes, tipos de embarcaciones, rutas, puertos de partida y de destino, escalas, compañías, etc.

\section{Cádiz: puerto atlántico medieval}

El puerto de Cádiz, ubicado en una privilegiada posición geográfica entre el Mar Mediterráneo y el Océano Atlántico, desempeñó un papel preeminente en las múltiples rutas comerciales desde la Antigüedad. La ciudad disponía de «condiciones óptimas para constituirse en escala obligada $\rangle^{13}$ tanto de las rutas que conectaban a las repúblicas mercantiles italianas con los puertos del Canal de la Mancha y del Mar del Norte como las que unían a las ciudades portuarias castellanas con el África occidental. Su éxito comercial y marítimo estaba estrechamente vinculado con la existencia de una bahía con suficiente calado que posibilitaba a los navíos refugiarse de las inclemencias meteorológicas. Como reveló Jacques Heers ${ }^{14}$, Cádiz fue el puerto de la Europa occidental más frecuentado por los navíos genoveses, donde se descargaban las mercancías procedentes de Oriente y se embarcaban atunes, mercurio, vinos, grana, productos de Berbería y de las Islas Atlánticas ${ }^{15}$. A pesar del papel predominante de Cádiz como el principal puerto del complejo portuario de la Baja Andalucía ${ }^{16}$, la gran plaza financiera y bancaria fue Sevilla ${ }^{17}$. Durante mediados del siglo XIV, este complejo portuario estaba dirigido por Algeciras ${ }^{18}$, Cádiz y Sevilla $\mathrm{y}$, asimismo, estaba integrado por otros puertos menos desarrollados en el siglo XIV, pero que alcanzaron una intensa actividad comercial y pesquera en el siglo XV, como

10 DOEHAERD (ed.), Les relations commerciales entre Gênes, la Belgique et l'Outremont, d'après les archives notariales génoises aux XIIIe et XIVe siècles.

11 Liagre de Sturler (ed.), Les relations commerciales entre Gênes, la Belgique et l'Outremont, d'après les archives notariales génoises, 1320-1400.

12 RenouARD, reseña del libro Les relations commerciales entre Gênes, la Belgique et l'Outremont, d'après les Archives notariales génoises, aux XIIIe et XIVe siècles de Renée Doehaerd, pp. 464-467.

13 Pérez-EmBid, "Las escalas ibéricas del Mediterráneo al Mar del Norte", pp. 265-290. La cita textual en p. 279.

14 HeErs, Gênes au XVe siècle. Activité économique et problèmes sociaux, p. 484.

15 NicolinI, Angelo, "Commercio marittimo genovese in Inghilterra nel Medioevo (1280-1495)", p. 233.

16 Отте, Sevilla y sus mercaderes..., p. 106.

17 D'Arienzo, "Le relazioni tra Genova...", p. 738.

18 Martín Gutiérrez, "El Estrecho de Gibraltar en el siglo XIV: Redes comerciales en Algeciras", pp. 51-69. 
Sanlúcar de Barrameda, El Puerto de Santa María, Tarifa y Rota. En el caso concreto de Cádiz, durante las primeras décadas del siglo XIV, actuó como puerto auxiliar de Sevilla. No obstante, con el transcurso del siglo, adquirió un carácter propio dentro de la navegación de las marinas italianas, si bien, logró su preponderancia en el siglo XV. Desde el siglo XII, el puerto de Cádiz comenzó a dar muestras de una apreciable actividad comercial, como consecuencia del despliegue de las rutas marítimas hacia Occidente ${ }^{19}$. El almirante de la flota almohade, 'Alí b. Maymün, convirtió a Cádiz en una auténtica ciudad portuaria ${ }^{20}$. En este contexto, debieron iniciarse las actividades mercantiles de los genoveses en el puerto gaditano. Tras la desintegración del Imperio almohade, los mercaderes ligures siguieron operando en la zona, como confirma el ataque a embarcaciones genovesas en el puerto de Cádiz por parte de los "calcurini" en 1234, recogido en los Annales de Caffaro ${ }^{21}$.

La conquista castellana de la Andalucía occidental permitió incorporar al puerto de Cádiz al sistema de redes portuarias de la Europa atlántica, sin abandonar sus relaciones mercantiles con el Mediterráneo musulmán. Este hecho unido a la apertura de la ruta de Poniente, le permitió establecerse como escala de los intercambios mercantiles europeos. Desde 1260, la ciudad y su puerto adquirieron gran protagonismo a raíz de la conquista por finalidades comerciales y militares. Cádiz se constituyó como base naval de la flota castellana para las operaciones en el Norte de África. Con el propósito de impulsar el despliegue de las actividades marítimas, el rey Alfonso X concedió a la ciudad gaditana la autorización para establecer una feria anual de un mes de duración y, asimismo, la exención de algunos impuestos como el portazgo y la "maltolta"22. A pesar de estas exenciones fiscales, los intercambios comerciales se vieron perjudicados por la proximidad de la frontera.

En los albores del siglo XIV, más allá de la órbita genovesa, el puerto gaditano desempeñó un papel relevante en el paso del Mediterráneo al Atlántico de la muda de Poniente. A partir de 1315 , las galeras venecianas comenzaron a surcar la ruta de Poniente con motivo de la inauguración de la línea de Flandes ${ }^{23}$. Según Doris Stöckly, entre 1324-1347, la ruta de la línea de Flandes parece establecida en el siguiente itinerario: Venecia, Sicilia, Mallorca, Cádiz, Lisboa, Inglaterra, La Esclusa, Brujas, Brabante. En efecto, la flota veneciana, compuesta de cuatro a ocho galeras, disponía de dos a cuatro días para fondear en el puerto gaditano antes de dirigirse hacia Lisboa y, posteriormente, al Mar del Norte.

19 Simbula, "Apertura de las rutas comerciales de las flotas italianas hacia el Atlántico", p. 211.

20 Picard, La Mer des Califes: Une historie de la Méditerranée musulmane, p. 347.

21 Perche arriuati all'Isola di Cales, e trouati alcuni legni Genouefi gli prefero, e infiememente fecero prigioni gli haomini, che erano Sopra di effi, che erano cittadini Genouesi nati di nobil fangue. Texto procedente del facsímil de la obra de U. Foglietta, recogido en Mosquera Merino, La Señoría de Ceuta en el siglo XIII (Historia política y económica), p. 108.

22 González Jiménez, "Cádiz en el siglo XIII...", pp. 747-758.

23 Sin ánimos de ser exhaustivos, sobre el sistema estatal de las galeras venecianas: LóPEZ DE COCA CASTAÑER, "Sobre las galeras venecianas de poniente y sus escalas ibéricas (siglo XV)", pp. 401-416; "La "muda" de Berbería en las fuentes españolas", pp. 361-401; "Las galeras venecianas de Poniente y Berbería desde la perspectiva española", pp. 113-172. 
El sistema estatal de galeras se vio perjudicado por los diversos conflictos bélicos, principalmente, la Guerra de los Cien Años y la Guerra de Chioggia. A partir de 1384, una vez que el sistema estatal estuvo reordenado, las galeras venecianas de la muda de Poniente, constituidas por 4 o 5 galeras, podían fondear en el puerto de Cádiz durante dos días ${ }^{24}$.

La correspondencia conservada en el Archivo Datini de Patro, analizada por Raúl González Arévalo ${ }^{25}$, ofrece más referencias sobre las actividades comerciales de los genoveses en la ciudad de Cádiz a fines del siglo XIV. En marzo de 1394, el florentino Vieri di Francesco Gori afirmó que había llegado al puerto de Cádiz en la nave del genovés Francesco Vacca que procedía de Southampton donde había estibado paños ingleses. Poco más tarde, escribió otra carta a Génova informando de la presencia en el puerto gaditano de cuatro embarcaciones genovesas, lideradas por Bernabò d'Anttuna (ruta Flandes-Romania), Attaviano Larcharo (Flandes-Romania), Alberto da Rusciano (Inglaterra-Génova) y Alberto Malagamba (Cádiz-Génova) ${ }^{26}$.

Las últimas referencias sobre las actividades comerciales-marítimas en el puerto de Cádiz en el siglo XIV datan de 1395-139627. Resulta llamativo el silencio de las fuentes durante los últimos años del Trescientos. Quizás, esta circunstancia está fuertemente relacionada con el suceso de 1397, cuando la flota portuguesa asaltó el puerto e incendió sus instalaciones ${ }^{28}$. Es evidente que este ataque al puerto y sus infraestructuras tuvo un profundo impacto en el desarrollo de las actividades mercantiles. No obstante, parece ser que las galeras venecianas de la línea de Flandes siguieron previendo una parada en el puerto de Cádiz durante los últimos años del siglo XIV ${ }^{29}$. Si bien, en las actas notariales genovesas del siglo XV, recopiladas por Renée Doehaerd y Charles Kerremans, no hallamos ninguna referencia a Cádiz hasta $1405^{30}$.

\section{Cádiz y la navegación genovesa}

La conquista de las ciudades de Sevilla y de Cádiz resultó de vital importancia para la expansión comercial de las marinas italianas hacia el Norte de Europa ${ }^{31}$. Para cruzar el Estrecho de Gibraltar desde el mar Mediterráneo era esencial disponer de puertos de apoyo, que permitieran a las embarcaciones, por un lado, su defensa en caso de un posible

\footnotetext{
24 Stöckly, Le système de l'Incanto des galées du marché à Venise, fin XIII ${ }^{e}$-milieu XV siècle, p. 153.

25 GonzÁlez ArÉvalo, "Florentinos entre Cádiz...", passim.

26 Ibídem, pp. 282-283.

27 1395: Liagre de Sturler, doc. 590 (La Esclusa-Cádiz-Génova). En noviembre de 1397, Luca del Biondo estaba en Cádiz para dirigirse a Brujas. Esta referencia procedente de la documentación del Archivo Datini de Patro, ha sido recogido en Houssaye Michienzi, Datini, Majorque et le Maghreb (14 ${ }^{e}-15^{e}$ siècles), p. 352.

28 Bello León, "Apuntes para el estudio de la influencia del corso y la piratería en la política exterior de los Reyes Católicos”, p. 69. SÁnchez Saus, "Cádiz en época...”, p. 234. Medrano Fernández, Un mercado entre fronteras: Las relaciones comerciales entre Castilla y Portugal al final de la Edad Media, p. 346.

29 STÖcKly, Le système de l'Incanto..., p. 163.

30 1405: Doenaerd-Kerremans, doc. 13 (Rodas-Málaga-Cádiz-Southampton-La Esclusa).

31 Heers, "Les hommes d'affaires italiens en Espagne au Moyen Âge: le marché monétaire”, p. 75.
} 
ataque de una flota enemiga y, por otro, su refugio ante las dificultades meteorológicas ${ }^{32}$. La primera referencia documental sobre la apertura de la ruta atlántica por las marinas italianas data de 1277, cuando la galera del patrón genovés Nicolozzo Dugus Spinola ${ }^{33}$ se aventuró a cruzar las Columnas de Hércules para dirigirse, tras haber realizado escala en Cádiz y Sevilla, hacia Flandes ${ }^{34}$. La inauguración de esta ruta causó el declive de las ferias de Champaña y de los itinerarios terrestres que se vieron afectados por las ventajas que ofrecía el transporte marítimo: más rapidez, menor coste, mayor tonelaje ${ }^{35}$. A pesar de que a finales del siglo XIII fueron frecuentes los contactos entre el Mediterráneo y el Atlántico, ${ }^{36}$ no será hasta mediados del siglo XIV, con el control cristiano del Estrecho de Gibraltar por las flotas castellanas y catalanas, cuando se incrementen inusitadamente los intercambios comerciales entre las repúblicas mercantiles italianas y las ciudades del Norte de Europa -Brujas, Middelbourg, Londres, Southampton-, revelándose Cádiz como una escala imprescindible de esta ruta marítima.

Durante la primera mitad del siglo XIV, se constata la presencia de embarcaciones genovesas surcando el puerto gaditano. En 1310, Graciadeus de Nigro y sus socios Oberto Pecolus y Andalo Zurlus, estipularon que sus galeras, San Cristoforo y San Giovanni, estaban dispuestas para partir hacia Inglaterra y Flandes cargadas con doscientas setenta y dos cántaros de algodón ${ }^{37}$. En la preparación previa al viaje, se concertó la escala en Mallorca y en Cádiz, antes de la llegada definitiva a los puertos del Norte de Europa. Resulta conveniente afirmar que no se trataba de un viaje redondo GénovaInglaterra/Flandes, el puerto gaditano se constituye como el eje fundamental de estos viajes $^{38}$. Desde Cádiz navegan a Inglaterra y Flandes, para regresar al puerto gaditano donde estiban las mercancías y aproan rumbo de nuevo hacia el Norte de Europa, para, posteriormente, realizar el mismo recorrido de regreso hacia Génova. En este sentido, resulta necesario afirmar que las galeras genovesas navegaban en doble ruta: por la costa o en derrota hacia Mallorca y Cádiz ${ }^{39}$. Poco tiempo después, en 1317, Sepionus de Nigro fletó su nave, San Niccolò, fondeada en el puerto de Cádiz, a Nicolinus Ususmaris y Antolinus Pesagno para transportar trigo africano a Southampton o Sandwich ${ }^{40}$.

\footnotetext{
32 Rozas Español, "La ruta atlántica (siglos XIII-XIV): análisis de la formación de una ruta comercial", pp. 485-504.

33 Doenaerd, "Les Galères génoises dans la Manche et la Mer du Nord à la fin du XIII" et au début XIV s.”, pp. 5-76, concretamente, p. 10.

34 Simbula, "Apertura de las rutas comerciales...", p. 239.

35 Igual Luis, "Comunicación y transporte en la Europa medieval: valoraciones, sectores, evolución", p. 78-79.

36 Desde finales del siglo XIII son numerosos los barcos que cruzan el Estrecho de Gibraltar para navegar los puertos mediterráneos y atlánticos. Sirva el siguiente ejemplo: en 1292, Carlotto y Andalo de Negro, patrones de la coca San Siro, cargaron alumbre en Focea para después descargarlo en Cádiz y, posteriormente, en Brujas. Balard, La Romanie génoise (XII -début du XV siècle), vol. II, p. 556.

37 Doeahaerd, "Les Galères génoises dans la Manche...", doc. 23, 23bis; Les relations commerciales..., vol. III, doc. 1682-1685, 1688-1689.

38 Ortega Villoslada, "Mallorca y el comercio atlántico. Siglos XIII-XIV”, p. 68.

39 Ortega Villoslada, El Reino de Mallorca y el mundo atlántico (1230-1349), Ed. Netbiblo-UNED, Oleiros (La Coruña), 2010, p. 66.

40 Doenaerd, "Les Galères génoises dans la Manche...", doc. 34; Les relations commerciales..., doc. 1858.
} 
Estas son, por el momento, las únicas actas notariales genovesas que aluden, de una forma u otra, al puerto gaditano en el período comprendido entre 1300-1340. Por un lado, aparece como escala de los navíos que surcaban la ruta atlántica y como punto de desembarque de mercancías. Y, por otro, se presenta como fondeadero de las embarcaciones genovesas y como punto de partida de los viajes comerciales hacia el Norte de África. Esta escasez documental es una consecuencia directa a la Guerra del Estrecho. Este conflicto bélico bloqueó la navegación de las rutas marítimas entre el Mediterráneo y el Atlántico. No será hasta la década de 1340, cuando las menciones al puerto de Cádiz se multipliquen, como consecuencia del control del Estrecho de Gibraltar por los castellanos.

Durante la década de los años cuarenta y cincuenta del siglo XIV, se han hallado embarcaciones genovesas en Cádiz en los siguientes años: 1343 (2), 1345 (1), 1347 (1), 1348 (2), 1349 (2), 1350 (2). Entre los años 1351-1369, por ahora, no disponemos de ninguna información sobre la presencia de navíos de Génova. No cabe duda de que estos años estuvieron afectados por la expansión de la peste negra y por el conflicto bélico de la Guerra de los Dos Pedros. Tanto uno como otro provocaron interrupciones comerciales. En este contexto, es necesario suponer la presencia de naves genoveses en Cádiz durante la década de los años cincuenta, tal como revela la carta enviada por los "consell e els mercaders catalans", residentes en Sevilla, a los jurados y "consellers" de Valencia en 1353, informándoles de la llegada de naves genovesas al puerto de Cádiz ${ }^{41}$. En las últimas décadas del siglo XIV, la situación cambió, produciéndose un período de auge para las relaciones comerciales entre Génova y las ciudades de la Europa atlántica. En efecto, hemos hallado la presencia de barcos genoveses en Cádiz en los siguientes años: 1370 (2), 1381 (1), 1383 (1), 1384 (3), 1386 (2), 1388 (2), 1393 (1), 1394 (5), $1395(1)^{42}$. Como se ha supuesto anteriormente, la presencia de navíos ligures tuvo que ser superior al número aportado por la documentación genovesa recopilada. En este sentido, los registros documentales del Archivo de la Corona de Aragón arrojan cierta luz sobre este asunto. Así, en 1395, hallamos el ataque a la nave de Nicolau Madrenchs, mercader barcelonés, por parte de tres navíos genoveses en el puerto gaditano ${ }^{43}$. Antes de dirigirse hacia el Mar del Norte, las embarcaciones genovesas hacían escala en los puertos de la Península Ibérica, fundamentalmente, en Málaga y Cádiz. Desde el puerto gaditano, las naves navegaban hacia La Esclusa, tal como reflejan los protocolos notariales:

Causa eundi ad Cadexim de Ispanie et pro rata ipsius, et rixicum incipiat in ipsa hora et incipisse inteligatur et sic stet et duret in dicta cocha donec in Cadexim fuerit aplicata et sic ibídem stando exonerando et de reonerando,

\footnotetext{
41 Diago Hernando, "Relaciones comerciales de la Corona de Aragón con la Andalucía atlántica durante el siglo XIV y primera mitad del siglo XV", p. 29.

42 Ver Tabla 1.

43 Diago Hernando, "Relaciones comerciales de la Corona de Aragón...”, p. 47.
} 
stando et eundo in alio navigio de Cadexi usque ad dictum locum de Cluxis in quo fuerit oneratum dictum locum de Cluxis in quo fuerit oneratum dictum meum alumen et prime partis ipsius que primo sic in dicto loco de Cadexi in alio navigio fuerit onerate ${ }^{44}$.

Resulta difícil precisar el principal itinerario de estos navíos, entre otros motivos, porque la ruta y las escalas respondían a la iniciativa estrictamente privada de los propios genoveses, al contrario de los venecianos y florentinos, cuyos itinerarios estaban normalizado por el Estado. Aún así, existen similitudes entre las diferentes rutas analizadas, parece que el itinerario más preponderante fue: Génova-Cádiz-La Esclusa (Brujas). Este hecho refleja el interés de los genoveses por reducir considerablemente el número de etapas en la ruta de Poniente. Tanto Jacques Heers ${ }^{45}$ como Raúl González Arévalo ${ }^{46}$ han podido comprobar que en el siglo XV los viajes genoveses con destino a Inglaterra y Flandes, en la mayoría de las ocasiones, realizaban una única escala en Cádiz. Parece ser que este hecho fue habitual desde la primera mitad del siglo XIV. No obstante, la ruta podría ser complementada con escalas intermedias en Nápoles, Mallorca, Ibiza, Alicante, Almería, Málaga, Algeciras -antes de su destrucción en 1379-, Lisboa. Los genoveses pudieron suprimir escalas intermedias en sus trayectos marítimos gracias al empleo de grandes navíos ${ }^{47}$. El punto final de la navegación atlántica era, en la mayoría de los casos, el puerto de Brujas, La Esclusa.

Aunque, estos itinerarios tenían como punto de partida la ciudad de Génova, desde finales del siglo XIII los mercaderes genoveses desarrollaron la ruta que unían FoceaQuíos con La Esclusa-Inglaterra-Middelbourg, que supuso la supresión de la estación en Génova, dirigiéndose directamente hacia Cádiz, única escala antes de afrontar el Océano Atlántico ${ }^{48}$. Al igual que los viajes de ida, resulta difícil establecer un itinerario único en el tornaviaje. Es bien cierto que las embarcaciones pretendieron quemar etapas con el fin de aligerar el viaje. En la mayoría de los casos, parece ser que las naves genovesas que partían desde el Norte de Europa, principalmente de La Esclusa y Southampton, se detenían en Cádiz antes de dirigirse a Génova. Sólo en una ocasión hemos hallado un viaje con más escalas: en 1347, la coca San Antonio del patrón Segurano Mariono marchó desde La Esclusa hacia Génova, realizando escala en Cádiz, Algeciras, Málaga, Almería, Alicante, Ibiza, Mallorca. En torno al 1400 un viaje desde Southampton a Cádiz, en circunstancias favorables, solía tener una duración aproximada de diez días ${ }^{49}$.

En cuanto a la tipología naval, la embarcación empleada con mayor frecuencia en los intercambios comerciales entre el Mar Mediterráneo y el Océano Atlántico fue, indudablemente,

\footnotetext{
1349: Liagre de Sturler, doc. 250 (Génova-Cádiz-La Esclusa).

Heers, Gênes..., p. 296.

GonZÁlez Arévalo, "En el Mediterráneo atlántico...", en prensa.

Chiappa Mauri, "Il commercio occidentale di Genova nel XIV secolo", p. 580.

Balard, La Romanie génoise..., p. 867.

49 FRYDE, "Italian maritime trade with England", p. 308.
} 
la coca - coche $-^{50}$, que sustituyó a la galera a mediados del siglo XIV, convirtiéndose en el barco habitual de estos contactos. No obstante, la galera continuó frecuentando la ruta de Poniente, como se puede comprobar en el caso de la muda de Flandes. Además de la coca, los genoveses utilizaron otros tipos de embarcaciones como la carraca -carracheo el pánfil -panfino ${ }^{-51}$. En numerosas ocasiones, no se puede conocer con precisión la tipología de la embarcación porque en los protocolos notariales aparecen con frecuencia el término genérico de navis. Resulta llamativo que, según la documentación analizada, solamente la familia de los Spinola dispusiera de carracas. Asimismo, en numerosas ocasiones, se documentan la utilización de una embarcación para realizar el trayecto por el Mar Mediterráneo y de otra para el recorrido por el Océano Atlántico. Así, en 1348, Domenico Oltremarino embarcaba una carga de 58 «vegetes» de vino en el pánfil de Niccolò Pinello para Andallo Maruffo desde Savona a Cádiz, posteriormente, la mercancía sería transbordada en una coca en el puerto gaditano con destino a La Esclusa ${ }^{52}$.

La escala de las embarcaciones genovesas en el puerto gaditano respondía a razones navales, comerciales y humanas: realizar una parada técnica antes de afrontar el Océano Atlántico ${ }^{53}$, la posibilidad de completar los fletes con mercancías andaluzas y norteafricanas, al mismo tiempo, que se solían descargar productos procedentes de Oriente -alumbre, algodón, especias o tintes-, para su posterior redistribución; reparar las embarcaciones o perfeccionar el avituallamiento de la tripulación y de los pasajeros y, finalmente, permitía a los navíos reclutar marineros y pilotos vascos o cántabros que dirigieran el barco hacia los puertos del Norte de Europa. La duración prevista de la escala estaba fijada por los contratos de fletamento, por esta razón, podía variar, aunque era asiduo que los navíos fondearan en el puerto gaditano durante dos o tres días, como así consta en el viaje de la coca San Bartolomeo del patrón Giacomo Dentuto en $1343^{54}$. Respecto a los seguros marítimos, tal como manifiesta la documentación notarial, era habitual que los transportes marítimos estuvieran protegidos por pólizas aseguradoras, cuyas tasas dependían del tipo de embarcación, el tonelaje, el armamento, el itinerario y sus condiciones, el cargamento, entre otros factores ${ }^{55}$. La necesidad de asegurar naves y mercancías responde al temor de incursiones piráticas pero, también, al posible naufragio de la embarcación. En ocasiones, los seguros marítimos no salvaguardaban la carga durante todo el transcurso del viaje, sino exclusivamente una etapa del mismo. Los seguros de los viajes entre La Esclusa y Génova o de La Esclusa a Sicilia, cubrían la carga, ocasionalmente, a partir del puerto de Cádiz al destino. En la última década del siglo XIV, un

\footnotetext{
50 Ortega Villoslada, «La coca en el intercambio mercante Atlántico-Mediterráneo», pp. 429-444.

51 El pánfil es una embarcación de menor tamaño que la galera, pero superior a la saetía, que disponía de dos mástiles y remos. Está documentada su presencia desde el siglo XIII, aunque su empleo se limitaba a las actividades comerciales del ámbito mediterráneo. Cf. ORTEGa Villoslada, La marina mercante medieval y la Casa de Mallorca: entre el Mediterráneo y el Atlántico, p. 297.

52 1348: Liagre de Sturler, doc. 227 (Savona-Cádiz-La Esclusa).

53 Petti Balbi, "Un binomio indisoluble: navegación comercial y armamento público en Génova en los siglos XIV-XV", p. 60.

54 1343: Liagre De Sturler, doc. 118, 123, 127 (Génova-Mallorca-Málaga-Cádiz-La Esclusa).

55 Cf. GonzÁlez ArÉvalo, "Corso, comercio y navegación...", p. 90-91.
} 
seguro marítimo de un viaje con una carga de paños, desde Cádiz con destino a Sicilia costaba 100 florines $^{56}$, mientras que de Cádiz a Génova costaba 200 florines $^{57}$, en ambos casos la carga había sido efectuada en el puerto de La Esclusa. Resulta llamativo que, en la mayoría de los casos, el seguro marítimo comenzará a funcionar a partir de la escala en el puerto gaditano, tanto en el viaje de ida como en el tornaviaje.

\section{Cádiz en los fletes de las embarcaciones genovesas}

Los fletes de Génova a Flandes e Inglaterra muestran que las mercancías tenían, exclusivamente, como destino, en teoría, los mercados de la Europa septentrional, es decir, sin que se vendieran en las escalas intermedias. No obstante, los productos podían ser mercadeados en los puertos atlánticos, porque, entre otros motivos, en los contratos marítimos se revela que estaba prohibido abandonar el puerto gaditano y navegar hacia el Norte con una carga superior a los 10.000 cántaros $^{58}$. Por esta razón, los mercaderes ligures aprovechaban los días de escala en el puerto de Cádiz para vender una parte de la mercancía.

¿Qué productos circulaban por esta ruta atlántica? De los contratos de fletamento analizados se desprende que el principal producto de estos intercambios comerciales fue el alumbre ${ }^{59}$, mineral indispensable de la industria textil. Según revela la documentación, los mercaderes genoveses comercializaban con diferentes tipos de alumbres: alumbre de roca -de origen turco-, alumbre «di sorta», de alumbre de Cotai - que era embarcado en Altoluogo (Éfeso) y Antalya- ${ }^{60}$ y, por último, el importado de las Islas de Lípari.

Una vez que obtuvieron el control sobre las minas de alumbre de Quíos, los mercaderes genoveses desempeñaron un papel predominante como intermediarios en su exportación hacia los mercados de la Europa atlántica ${ }^{61}$. El comercio genovés del alumbre posibilitó la configuración de una nueva ruta marítima que conectaba al Mediterráneo oriental con el Mar del Norte, revelándose el puerto gaditano como una escala fundamental de este itinerario. Efectivamente, el transporte de once cántaros de alumbre desde Constantinopla hasta el puerto de Cádiz era de tres florines de oro $^{62}$ :

\footnotetext{
1393: Liagre de Sturler, doc. 577 (La Esclusa-Cádiz-Isla de Sicilia).

1395: Liagre de Sturler, doc. 590 (La Esclusa-Cádiz-Génova).

58 Dei impedimento remanserit, promitens tibi quod dicta cocha a dicto loco Cadese ultra eundo in dictum viagium non honerabitur aliquo modo nec in ipsam recipietur ad honus ultra pondus cantariorum decem millium ad pondus et cantarium de Janua... 1343: Liagre De STURLer, doc. 123 (Génova-Mallorca-Málaga-Cádiz-La Esclusa). Con anterioridad, los musulmanes habían establecido una relevante regulación sobre la capacidad de carga de las diversas embarcaciones, incluso llegó a existir la figura del muhtasib, quien se encargó de inspeccionar el cargamento del barco para evitar la sobrecarga y un posible naufragio. Los navíos musulmanes disponían de una "línea de carga" que indicaba la profundidad de calado, en el caso de que las embarcaciones no cumplieran esta normativa podían llegar a ser penalizadas. KHALILIEH, Admiralty and Maritime Laws in the Mediterranean Sea (ca. 800-1050). The Kitāb Akriyat al-Sufun vis-à-vis the Nomos Rhodion Nautikos, pp. 36-40. Agradezco a la amiga y colega, Marta Del Mastro Burgos que me indicara esta información.

59 Igual Luis, "La producción y el comercio del alumbre en los reinos hispánicos del siglo XV”, pp. 259-276.

60 ChiapPa Mauri, "Il commercio occidentale di Genova nel XIV secolo", p. 607.

61 HeErs, "Il comercio nel Mediterraneo alla fine del sec. XIV e nei primi anni del XV”, pp. 170-173.

62 GonzÁlez Arévalo, "Comercio exterior del Reino...,", p. 231.
} 


\begin{abstract}
[Bruggia] con Cadisi di Spagna
Ragionasi che costi a conducere allume in navilio disarmato da Cadisi a bruggia fiorini 3 d'oro il migliaio grosso di Gostantinopoli, ch'è cantara 11 e ruotoli 11 di Gostantinopoli.

Il detto cantaro è tutt'uno peso con quello di Genova.
\end{abstract}

Asimismo, el algodón procedente de Oriente -concretamente de Alejandría y Quíos-63 constituía una de las mercancías más demandadas por los mercados europeos. Era transportado desde Génova hasta Málaga y Cádiz, posteriormente, era destinado hacia Flandes $^{64}$. En 1343, Giacomo Dentuto, patrón de la coca San Bartolomeo, reconoció haber recibido tres balas de algodón de Alessandro Doria ${ }^{65}$. De forma similar, los venecianos cargaban algodón y fustanes que tenían como destino Brujas y Londres, aunque una parte menor podía ser descargada en los diferentes puertos que componían el itinerario de la línea de Flandes. Así, en 1396, las galeras venecianas descargaron ocho piezas de fustán milanés en Cádiz, antes de dirigirse hacia el Norte de Europa ${ }^{66}$.

En el flujo comercial entre el Norte y el Sur de Europa, las especias ocuparon un lugar preeminente. En 1381, Stefano Doria reconocía tener de Andrea Maruffo una carga de pimienta que tenía como destino La Esclusa, aunque una parte sería vendida en los mercados de Marsella, Almuñécar, Vélez-Málaga, Málaga y Cádiz ${ }^{67}$. Esta acta notarial releva la elevada importación de especias en el Reino nazarí de Granada, puesto que de las siete escalas que componen el viaje, tres se corresponden con la costa nazarita. Quizás, este Stefano Doria sea el mismo que en 1435, junto con Jeronimo de Fornario y Giovanni Italiano, solicitaron ayuda a los administradores genoveses de la Sociedad de la Fruta - con base en el Reino de Granada y controlada por la familia de los Spinola- en Málaga y Almuñécar ante posibles ataques piráticos ${ }^{68}$.

Desde la década de 1340 está documentada la importación de lana y paños ingleses y flamencos en Castilla que, posteriormente, eran exportados a través de los puertos atlánticos andaluces ${ }^{69}$. Los mercaderes genoveses desempeñaron un papel preeminente en el transporte de paños hacia el Sur de Europa. En efecto, en 1393, Napoleone Doria cargaba una pieza de paños de Wervicq ${ }^{70}$ en la nave de Pietro Camilla, que estaba anclada en el puerto de La Esclusa, para Battista Lomellino ${ }^{71}$. A finales del siglo XIV, los mercaderes

\footnotetext{
63 Nam, Le commerce du coton en Méditerranée à la fin du Moyen Age.

64 Ibídem, p. 309.

65 1343: Liagre de Sturler, doc. 127 (Génova-Mallorca-Málaga-Cádiz-La Esclusa).

66 NAM, Le commerce du coton..., p. 47.

67 1381: Liagre de Sturler, doc. 382 (Génova-Marsella-Almuñécar-Vélez-Málaga-Cádiz-La Esclusa).

68 Salicrú i Lluch, "Génova y Castilla, genoveses y Granada. Política y comercio en el Mediterráneo occidental en la primera mitad del siglo XV (1431-1439)", p. 55.

69 Pardessus, Collection des lois maritimes antérieures au XVIII siècle, tomo III, p. CI.

70 Iradiel Murugarren, Evolución de la industria textil castellana en los siglos XIII-XVI. Factores de desarrollo, organización y costes de la producción manufacturera en Cuenca, p. 38, 121, 131.

71 1393: Liagre de Sturler, doc. 577 (La Esclusa-Cádiz-Isla de Sicilia).
} 
de Génova cargaban paños ingleses en el puerto gaditano con destino a la isla de Rodas con una prima del $51 / 3 \%^{72}$. También, las embarcaciones genovesas solían cargar aceite sevillano en el puerto de Cádiz que tenía como destino Pera y Constantinopla. Este aceite era trasladado desde Sevilla a Cádiz, donde se cargaba en las naves ancladas en su puerto ${ }^{73}$. Asimismo, desde el siglo XIV, en el flete de retorno, los barcos genoveses solían embarcar en Cádiz, sal y atún procedente de las almadrabas gaditanas ${ }^{74}$.

\section{Los pilotos vascos}

Las diversas condiciones de la navegación atlántica obligaron a los patrones italianos a recurrir, en numerosas ocasiones, a pilotos especializados en esta área marítima para conducir las naves hasta los puertos de Flandes e Inglaterra ${ }^{75}$. Tanto los marinos vascos como cántabros destacaron por sus amplios conocimientos del litoral, de los fondos, del régimen de vientos o de las corrientes ${ }^{76}$. Esta circunstancia les concedió la posibilidad de intervenir activamente en el transporte de mercancías por vía marítima, a causa de que los patrones genoveses reclutaron pilotos que supieran navegar el mar di Spagna ${ }^{77}$. Antes de iniciar el tramo atlántico hacia La Esclusa, los navíos genoveses fondeaban en el puerto de Cádiz, donde se reclutaba a los pilotos expertos, cuya función, en la mayoría de las ocasiones, se limitaba a conducir la nave por el Océano Atlántico. Así, en 1370, el piloto cántabro, Juan García de Castañeda se enroló en la coca del patrón Manuele Vento, con el fin de conducir la embarcación desde Cádiz a La Esclusa en el viaje de ida y desde La Esclusa a Cádiz en el viaje de vuelta. El piloto recibió la cantidad de 100 escudos de oro en concepto de salario ${ }^{78}$.

Los pilotos vascos se encargaron de dirigir las naves genoveses con gran frecuencia en la ruta atlántica. Así, por ejemplo, en 1383, Juan Ibáñez de Gacito de Berango fue reclutado para conducir la nave castellana de Barnaba Dentuto desde Génova hasta Flandes en la ida y hasta el puerto gaditano en la vuelta. Este piloto recibiría una indemnización económica en el caso de que la nave permaneciera más de dos meses en Flandes ${ }^{79}$. Un año más tarde, el piloto vasco Ochoa de Guetaria se encargó de conducir la nave de

\footnotetext{
72 Balard, Gênes et la mer. Genova e il mare, vol. I, p. 251.

73 GonzÁlez Arévalo, "Comercio exterior del Reino...”, op. cit., pp. 224, 242.

74 Aunque en las actas notariales se ha hallado ninguna referencia sobre el embarque de sal en el puerto de Cádiz, Enrique Otte afirmó en su obra culmen que los mercaderes genoveses se abastecieron de sal de Ibiza y de Cádiz. Cf. Oтte, Sevilla y sus mercaderes..., p. 121. De igual forma, Juan Manuel Bello reveló las exportaciones de atún gaditano. $C f$. Bello León, "El Reino de Sevilla...”, op. cit., p. 79.

75 HeErs, "Le commerce des basques en Méditerranée au XVe siècle”, pp. 292-324. Ferrer i Mallol, "Transportistas y corsarios vascos en el Mediterráneo medieval. Las aventuras orientales de Pedro Larraondo (1406-1409)", pp. 509-524; "Los vascos en el Mediterráneo medieval. Los primeros tiempos”, pp. 115-128; VAQUERo PIÑEIRO, "Relaciones entre las villas cántabras de la costa y la Península Italiana en los siglos XIV y XV. Datos para su estudio", pp. 305-315; "Naves vascas en el puerto de Civitavecchia en la Baja Edad Media", pp. $207-234$.

76 Ferrer i Mallol, "Los vascos en el Mediterráneo...”, p. 116.

77 VAquero PiñeIro, "Naves vascas en el puerto...”, pp. 207-216.

78 1370: Liagre de Sturler, doc. 308 (Génova-Nápoles-Cádiz-La Esclusa).

79 1383: Liagre de Sturler, doc. 403 (Génova-Málaga-Cádiz-Flandes).
} 
San Niccolò del patrón Giuliano de Mari desde Génova hasta Southampton en el viaje de ida y, a la vuelta hasta Cádiz, Tarifa o Málaga. Por su labor recibió 100 francos de oro, aunque pudo obtener 5 doblas de oro más -si hubiera arribado al puerto de Cádiz o Tarifa- u 8 doblas -en el caso de que hubiera fondeado en Málaga-. Un aspecto interesante para tener en consideración es que este último piloto solicitó al patrón de la nave protección ante posibles ataques ingleses ${ }^{80}$.

\section{Consideraciones finales}

En la introducción de este trabajo, se afirmó que la historiografía había definido tradicionalmente al siglo XIV como "época de crisis»" ${ }^{81}$ No obstante, utilizando como campo de estudio el puerto de Cádiz y como fuentes las actas notariales genovesas, se ha podido testimoniar que el comercio internacional desarrolló una actividad notable en el Trescientos. Tal como se ha podido comprobar en este artículo, el siglo XIV estuvo marcado por períodos de crisis y de crecimiento. No debemos caer en el paradigma de "crisis depresiva", sino más bien, de "crisis de integración", como bien señaló Stephan R. Epstein ${ }^{82}$. Entre otros motivos, porque durante las últimas décadas de este siglo, las repúblicas mercantiles italianas incrementaron notablemente las relaciones comerciales con Flandes e Inglaterra. Este hecho benefició a los puertos del sur ibérico que quedaron perfectamente integrados en las rutas marítimas atlánticas. Este impulso comercial se prolongó hasta el siglo XV, siglo de mayor esplendor del comercio marítimo.

Desde la Baja Edad Media, el papel del puerto gaditano en las relaciones comerciales no dejó de acrecentarse. En efecto, los protocolos notariales ligures testimonian un relevante intercambio comercial entre Génova y Cádiz en el siglo XIV. En este sentido, es necesario insistir en el análisis sistemático de las actas notariales genovesas que permitirían avanzar en nuestro conocimiento sobre la ciudad de Cádiz en época medieval. No cabe duda de que es una investigación archivística ardua, puesto que la información se halla de forma desigual y dispersa, a lo que hay que añadir una intensa búsqueda de referencias bibliográficas, donde los puertos de la Andalucía atlántica no fueron el principal campo de estudio. Solo de este modo se podrán cubrir las lagunas documentales de las fuentes castellanas.

A lo largo del siglo XIV, el puerto gaditano va adquiriendo un carácter propio como centro fundamental en la navegación genovesa con destino al Norte de Europa. La ciudad desempeñó un papel fundamental en el desarrollo de las rutas atlánticas. Así, Cádiz se reveló como el puerto más importante del sur de la Península Ibérica y como eje de los intercambios comerciales entre Génova con Flandes e Inglaterra. El estudio realizado permite reiterar la relevancia que va a adquirir el puerto de Cádiz en el siglo XV.

1384: Liagre De Sturler, doc. 434, 437, 443 (Génova-Mallorca-Valencia-Málaga/Tarifa/Cádiz-La Esclusa).

81 Una nueva revisión sobre la crisis del siglo XIV y su relación con el comercio internacional: IGUAL LuIs, “¿Crisis? ¿Qué crisis? El comercio internacional en los reinos hispánicos de la Baja Edad Media”, pp. 203-223.

82 Epstein, Libertad y crecimiento: el desarrollo de los estados y de los mercados en Europa, 1300-1750. 
Mapa 1. Complejo portuario de la Baja Andalucía en el siglo XIV ${ }^{83}$

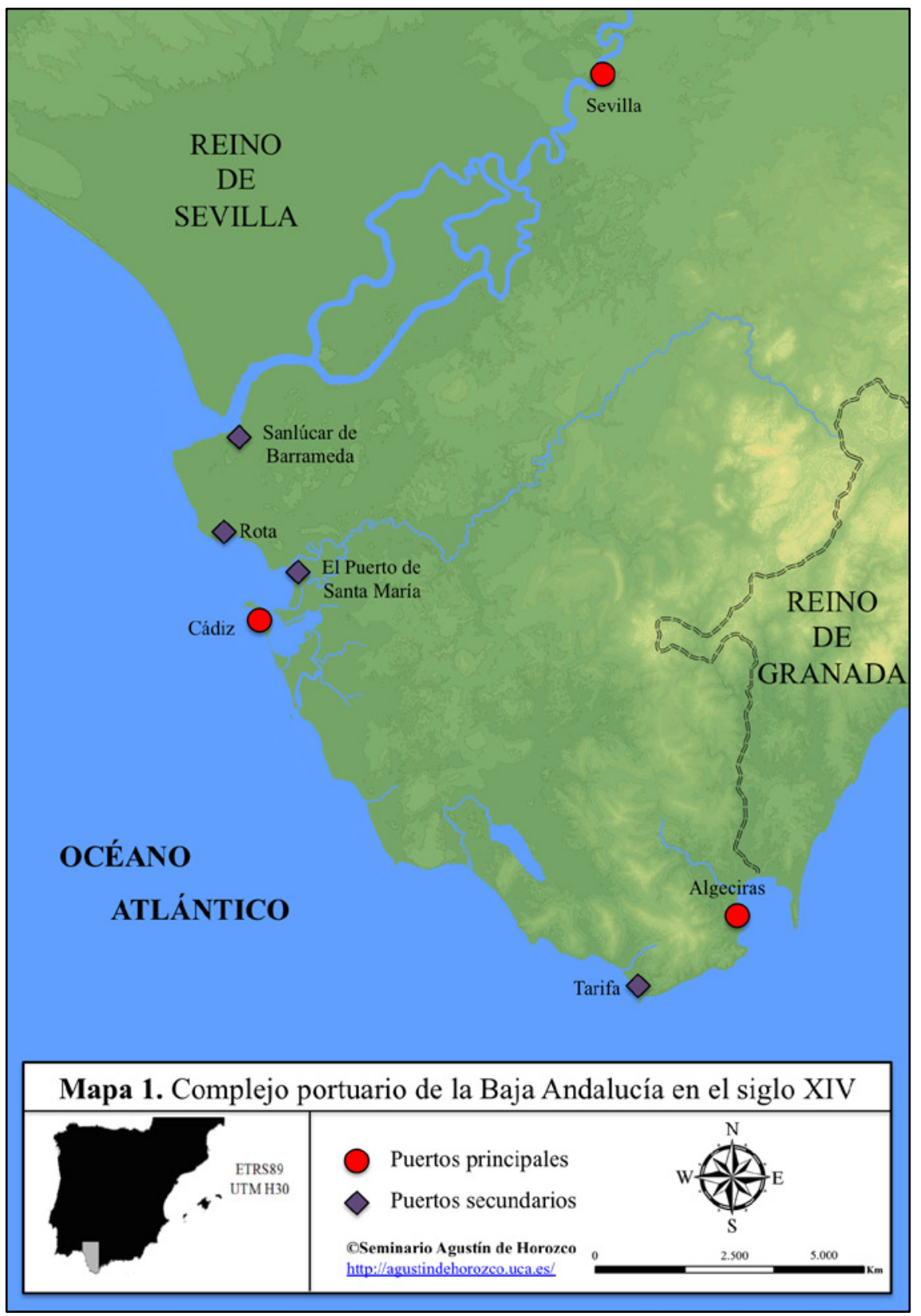

83 Elaborado a partir de MuÑoz GómEz, Víctor, "Puertos, abras, cabos e islas: la topografía medieval de la costa atlántica de Andalucía a través de las cartas portulanas (Ss. XIV-XVI)", pp. 179-211. 


\begin{tabular}{|c|c|c|c|c|c|c|c|c|c|c|c|c|c|c|c|c|c|}
\hline 量 & 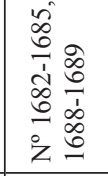 & $\begin{array}{l}\infty \\
0 \\
\infty \\
\infty \\
\dot{z}\end{array}$ & $\begin{array}{l}\stackrel{0}{\Xi} \\
\infty \\
\stackrel{0}{=} \\
\stackrel{\Xi}{\beth}\end{array}$ & $\begin{array}{l}0 \\
0 \\
-1 \\
0 \\
z \\
\end{array}$ & $\begin{array}{l}\stackrel{m}{I} \\
\stackrel{\circ}{Z}\end{array}$ & $\begin{array}{l}8 \\
\text { ते } \\
\text { Zे }\end{array}$ & 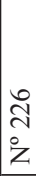 & 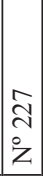 & $\mid \begin{array}{l} \\
\stackrel{2}{\sim} \\
i \\
Z\end{array}$ & $\left|\begin{array}{l}i \\
i \\
i \\
z\end{array}\right|$ & \begin{tabular}{|l}
$\overrightarrow{0}$ \\
$N$ \\
0 \\
$z$
\end{tabular} & $\begin{array}{l}0 \\
\text { ¿ } \\
\text { ¿ }\end{array}$ & $\mid \begin{array}{l}\infty \\
0 \\
\infty \\
\dot{z}\end{array}$ & $\begin{array}{l}\Delta \\
\stackrel{\Delta}{m} \\
\stackrel{z}{Z}\end{array}$ & 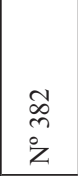 & 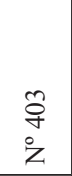 & 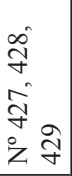 \\
\hline Uే & 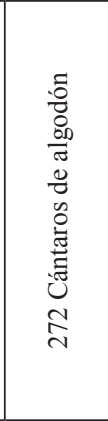 & 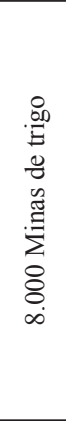 & 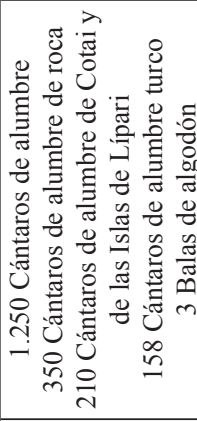 & & 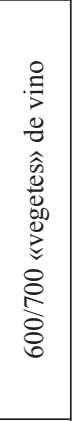 & & 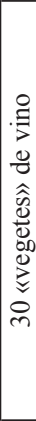 & 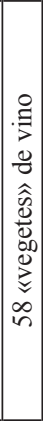 & 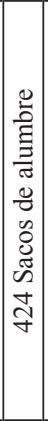 & 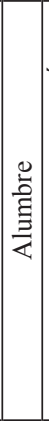 & 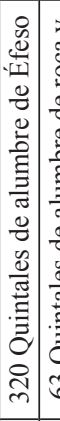 & 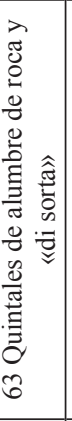 & & & 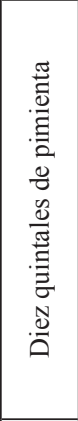 & & \\
\hline 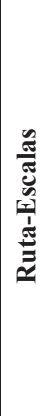 & 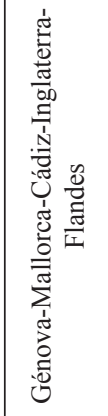 & 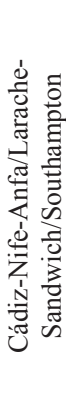 & 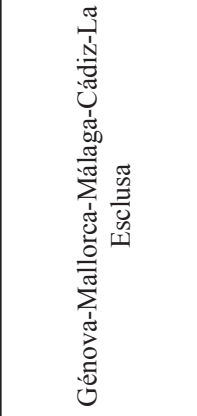 & 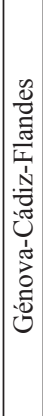 & 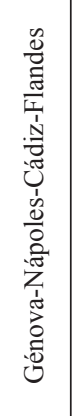 & 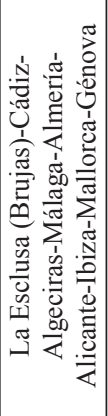 & 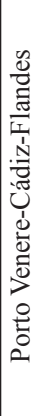 & 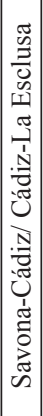 & 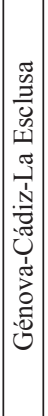 & 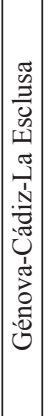 & 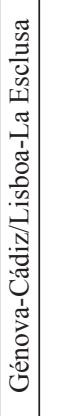 & 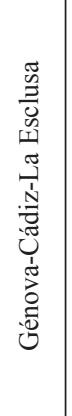 & 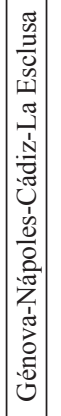 & 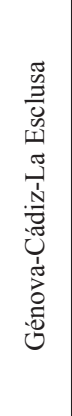 & 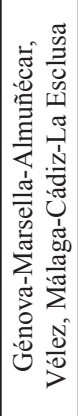 & 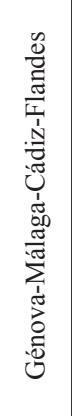 & 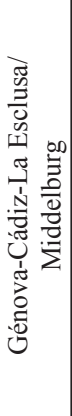 \\
\hline 总 & 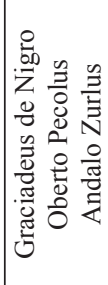 & 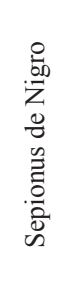 & 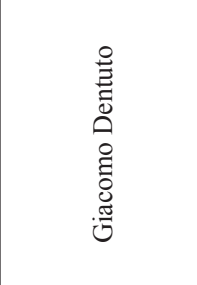 & 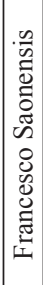 & 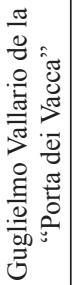 & 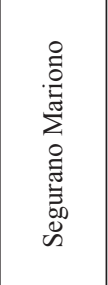 & 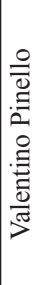 & 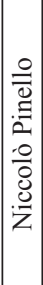 & 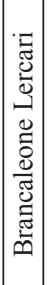 & 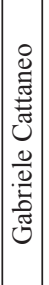 & 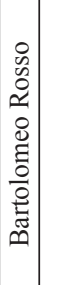 & 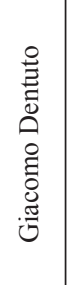 & 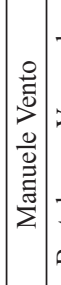 & 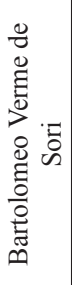 & 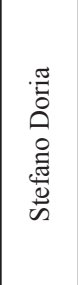 & 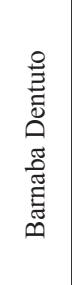 & 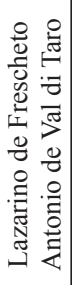 \\
\hline 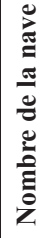 & 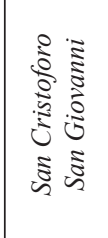 & 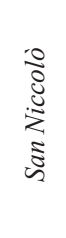 & 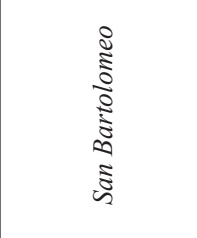 & 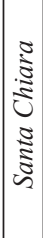 & 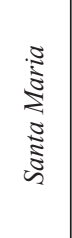 & 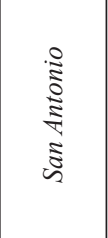 & & & 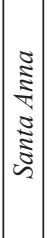 & & $\mid$ & 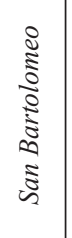 & & & $\begin{array}{l}8 \\
80 \\
5 \\
0 \\
5 \\
5 \\
5\end{array}$ & 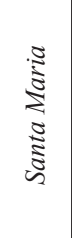 & \\
\hline z & $\frac{\stackrel{\mathscr{J}}{0}}{\frac{\pi}{\pi}}$ & 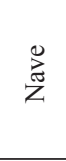 & ठூ & \begin{tabular}{|c|}
$\mid$ \\
$\tilde{J}$ \\
0
\end{tabular} & 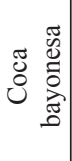 & ర్ల & : & 焉 & $\mid \begin{array}{l}8 \\
\tilde{8} \\
0\end{array}$ & $\mid \begin{array}{l}\pi \\
0 \\
0\end{array}$ & ठّ & ర్ల & ర్ల & ర్ & 己ั & 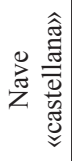 & ర్లే \\
\hline 竞 & $\stackrel{ }{\stackrel{m}{2}}$ & $\underset{\tilde{\Xi}}{\tilde{\Xi}}$ & $\stackrel{m}{\tilde{m}}$ & $\stackrel{\sim}{\emptyset}$ & $\stackrel{?}{m}$ & 怘 & I & $\stackrel{+}{m}$ & 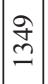 & 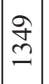 & $\begin{array}{l}\stackrel{i}{n} \\
m\end{array}$ & $\begin{array}{l}\stackrel{n}{n} \\
m\end{array}$ & 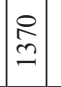 & $\stackrel{R}{m}$ & $\begin{array}{l}\vec{\infty} \\
\stackrel{n}{n}\end{array}$ & $\begin{array}{l}\tilde{\infty} \\
\stackrel{n}{=}\end{array}$ & $\begin{array}{l}\stackrel{+}{\infty} \\
ٍ\end{array}$ \\
\hline
\end{tabular}




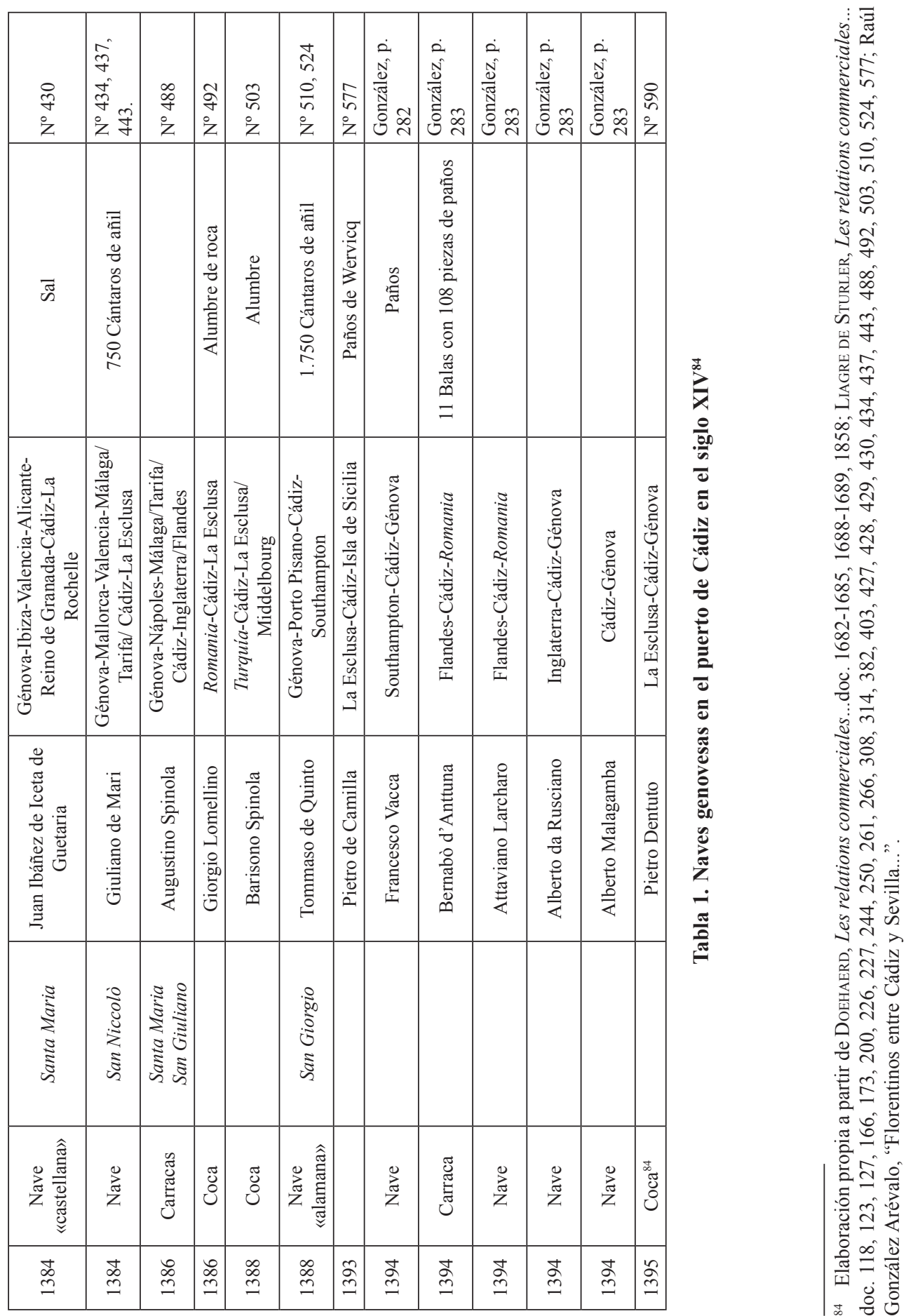




\section{Bibliografía citada}

Aznar Vallejo, Eduardo, “Cádiz y su región en la expansión atlántica”, Estudios de Historia y Arqueología medievales, 10 (1994), pp. 11-23.

Aznar Vallejo, Eduardo, “Andalucía y el Atlántico Norte a fines de la Edad Media”, Historia. Instituciones. Documentos, 30 (2003), pp. 103-120.

Balard, Michel, La Romanie génoise (XII -début du XVe siècle), Roma-Génova, vol. II, 1978.

Balard, Michel, Gênes et la mer. Genova e il mare, Società Ligure di Storia Patria, Génova, 2017, vol. I/II.

Bello León, Juan Manuel, "El Reino de Sevilla en el comercio exterior castellano (siglos XIV-XV)", Castilla y Europa: comercio y mercaderes en los siglos XIV, XV y XVI, Hilario Casado Alonso (coord.), Diputación Provincial de Burgos, Burgos, 1995, pp. 57-80.

Bello León, Juan Manuel, “Apuntes para el estudio de la influencia del corso y la piratería en la política exterior de los Reyes Católicos", Historia. Instituciones. Documentos, 23 (1996), pp. 63-97.

Chiappa Mauri, María Luisa, "Il commercio occidentale di Genova nel XIV secolo", Nuova Rivista Storica, 57(1973), pp. 571-612.

Collantes de Terán SÁnchez, Antonio, "Papel del Atlántico en la configuración de Andalucía", Historia. Instituciones. Documentos, 35 (2008), pp. 85-105.

D’ArIenzo, Luisa, "Le relazioni tra Genova e Cadice fra il XIII e il XV secolo", La Península Ibérica entre el Mediterráneo y el Atlántico. Siglos XIII-XV. Actas de las V Jornadas Hispano-Portuguesas de Historia Medieval, Cádiz, 1-4 abril de 2003, Manuel González Jiménez e Isabel Montes Romero-Camacho (eds.), Diputación Provincial de Cádiz-SEEM, Cádiz-Sevilla, 2006, pp. 733-745.

Diago Hernando, Máximo, "Relaciones comerciales de la Corona de Aragón con la Andalucía atlántica durante el siglo XIV y primera mitad del siglo XV", Historia. Instituciones. Documentos, 27 (2000), pp. 19-54.

DOEHAERD, René, "Les Galères génoises dans la Manche et la Mer du Nord à la fin du XIII et au début XIV s.", Bulletin de L'Institut Historique Belge de Rome, 19 (1938), pp. 5-76.

DOEHAERD, Renée (ed.), Les relations commerciales entre Gênes, la Belgique et l'Outremont, d'après les archives notariales génoises aux XIIIe et XIVe siècles, 3 vols., Institut Historique Belge de Rome, Bruselas, 1941.

Epstein, Stephan R., Libertad y crecimiento: el desarrollo de los estados y de los mercados en Europa, 1300-1750, Universitat de Valencia. Servei de Publicacions, Valencia, 2009.

FÁBregas García, Adela, Producción y comercio de azúcar en el Mediterráneo medieval. El ejemplo del Reino de Granada, Universidad de Granada, Granada, 2000. 
FÁbregas García, Adela, "Redes de comercio y articulación portuaria del Reino de Granada: puertos y escalas en el tráfico marítimo bajomedieval", Chronica Nova, 30 (2003-2004), pp. 69-102.

FÁbregas García, Adela, "La integración del reino nazarí de Granada en el espacio comercial europeo (siglos XIII-XV)", Investigaciones de Historia Económica, 6 (2006), pp. 11-40.

FÁbregas García, Adela, "Acercamiento y acuerdos comerciales entre Granada y Venecia al filo de 1400", Anuario de Estudios Medievales, 40/2 (2010), pp. 643-664.

FÁbregas García, Adela, "El reino nazarí de Granada como área de comercio internacional: ¿Colonia mercantil o espacio de integración?”, Anales de la Universidad de Alicante. Historia Medieval, 18 (2012-2014), pp. 153-169.

FÁBregas García, Adela, "Il regno nasride di Granada e i mercanti del Mezzogiorno italiano", Interscambi socio-culturali ed economici fra le città marinare d'Italia e l'Occidente dagli osservatorî mediterranei, Bruno Figlioulo y Pinuccia Simbula (eds.), Centro Di Cultura e Storia Amalfitana, Amalfi, 2014, pp. 333-349.

Ferrer i Mallol, María Teresa, "Transportistas y corsarios vascos en el Mediterráneo medieval. Las aventuras orientales de Pedro Larraondo (1406-1409)", Itsas Memoria. Revista de Estudios Marítimos del País Vasco, 2 (1998), pp. 509-524.

Ferrer i Mallol, María Teresa, "Los vascos en el Mediterráneo medieval. Los primeros tiempos", Itsas Memoria. Revista de Estudios Marítimos del País Vasco, 4 (2003), pp. 115-128.

FrYDE, Edmund B., "Italian maritime trade with England", Les grandes escales. Recueils de la Société Jean Bodin pour l'Historie comparartive des institutions, XXXII (1972), pp. 291-337.

González Arévalo, Raúl, "La costa del Reino de Sevilla en la documentación náutica italiana (siglo XV)", Historia de Andalucía. VII Coloquio, CD-ROM, 2010, pp. 301-317.

GonzÁlez Arévalo, Raúl, "Comercio exterior del Reino de Sevilla a través de los manuales de mercaderías italianos bajomedievales", Historia. Instituciones. Documentos, 38 (2011), pp. 221-255.

GonzÁlez ArÉvalo, Raúl, "Corso, comercio y navegación en el siglo XV: Castilla y las galeras mercantiles de Florencia", En la España Medieval, 34 (2011), pp. 61-95.

GonzÁlez ArÉvalo, Raúl, "Florentinos entre Cádiz y Sevilla en los siglos XIV y XV", De mar a mar. Los puertos castellanos en la Baja Edad Media, Eduardo Aznar Vallejo y Roberto José González Zalacaín (coords.), Universidad de La Laguna, La Laguna, 2015, pp. 273-307.

GonZÁLEZ Arévalo, Raúl, “Acordes y desacuerdos. Navegación y comercio de las galeras mercantiles de Venecia y Florencia en el Mediterráneo ibérico desde una perspectiva comparada", Navegación institucional y navegación privada en el Mediterráneo medieval, Raúl González Arévalo (ed.), Editorial Alhulia, Granada, 2016, pp. 145-191. 
GonzÁlez ArÉvalo, Raúl, "En el Mediterráneo atlántico: Andalucía y las marinas italianas en la ruta de Poniente (siglo XV)", en prensa.

GonzÁlez Jiménez, Manuel, "Cádiz en el siglo XIII: Historia de un proyecto frustrado", La Península Ibérica entre el Mediterráneo y el Atlántico. Siglos XIII-XV. Actas de las V Jornadas Hispano-Portuguesas de Historia Medieval, Cádiz, 1-4 abril de 2003, Manuel González Jiménez e Isabel Montes Romero-Camacho (eds.), Diputación Provincial de Cádiz-SEEM, Cádiz-Sevilla, 2006, pp. 747-758.

GonzÁlez Zalacain, Roberto José, "De puerto a puerto: las relaciones entre los puertos de la Bahía de Cádiz (Siglos XV-XVI), De mar a mar: Los puertos castellanos en la Baja Edad Media, Eduardo Aznar Vallejo y Roberto José González Zalacaín (coords.), Servicio de Publicaciones Universidad de La Laguna, San Cristóbal de La Laguna, 2015, pp. 147-177.

HeErs, Jacques, Gênes au XVe siècle. Activité économique et problèmes sociaux, S.E.V.P.E.N., París, 1961.

HeErs, Jacques, 'Les hommes d'affaires italiens en Espagne au Moyen Âge: le marché monétaire", Société et économie à Gênes (XIVe-XVe siècle), Londres, Varioum Reprints, 1979, VIII, pp. 74-83.

HeErs, Jacques, "Il comercio nel Mediterraneo alla fine del sec. XIV e nei primi anni del XV", Société et économie à Gênes (XIVe-XVe siècle), Londres, Varioum Reprints, 1979, pp. 157-209.

HeErs, Jacques, "Le commerce des basques en Méditerranée au XV siècle", Société et économie à Gênes (XIVe-XVe siècle), Londres, Varioum Reprints, 1979, pp. 292-324.

Houssaye Michienzi, Ingird, Datini, Majorque et le Maghreb $\left(14^{e}-15^{e}\right.$ siècles $)$, BRILL, Leiden-Boston, 2013.

Igual Luis, David, "Valencia y Sevilla en el sistema económico genovés de finales del siglo XV”, Revista d'Historia Medieval, 3 (1992), pp. 79-116.

Igual Luis, David, "Las galeras mercantiles venecianas y el puerto de Valencia, 13911534”, Anuario de Estudios Medievales, 24 (1994), pp. 179-200.

IGual LuIs, David, Valencia e Italia en el siglo XV: rutas, mercados y hombres de negocios en el espacio económico del Mediterráneo occidental, Bancaixa, Castellón, 1998. IguAl Luis, David, "La producción y el comercio del alumbre en los reinos hispánicos del siglo XV", MEFRM, 126/1 (2014), pp. 259-276.

IGuAl Luis, David, "Comunicación y transporte en la Europa medieval: valoraciones, sectores, evolución”, Una nueva visión de la Edad Media: legado y renovación, Esther López Ojeda (coord.), Instituto de Estudios Riojanos, Logroño, 2016, pp. 69-98.

Iradiel Murugarren, Paulino, Evolución de la industria textil castellana en los siglos XIII-XVI. Factores de desarrollo, organización y costes de la producción manufacturera en Cuenca, Salamanca, 1974. 
Khalilien, Hasan, Admiralty and Maritime Laws in the Mediterranean Sea (ca. 8001050). The Kitāb Akriyat al-Sufun vis-à-vis the Nomos Rhodion Nautikos, BRILL, Boston-Leyden, 2006.

Ladero Quesada, Miguel Ángel, "Unas cuentas en Cádiz (1485-1486)”, Cuadernos de Estudios Medievales II-III (1974-1975), pp. 87-120.

Liagre de StURler, Léone (ed.), Les relations commerciales entre Gênes, la Belgique et l'Outremont, d'après les les archives notariales génoises, 1320-1400, 2 vols., Institut Historique Belge de Rome, Bruselas, 1969.

Lopez, Roberto Sabatino, "Majorcans and Genoese on the North Sea Route in the Thirteenth Century", Revue belge de philologie et d'histoire, tomo 29, 4 (1951), pp. 1.163-1.179.

LÓPEZ De Coca CASTAÑer, José Enrique, "Sobre las galeras venecianas de poniente y sus escalas ibéricas (siglo XV)", Estudios en homenaje a Tomás Quesada, Universidad de Granada, Granada, 1998, pp. 401-416.

López de Coca CaSTAÑer, José Enrique, "La "muda" de Berbería en las fuentes españolas", Relaciones entre el Mediterráneo cristiano y el Norte de África en época medieval y moderna, Carmen Trillo San José (ed.), Alhulia, Granada, 2004, pp. 361-401.

López de Coca Castañer, José Enrique, "Las galeras venecianas de Poniente y Berbería desde la perspectiva española", Medievalismo, 16 (2006), pp. 113-172.

López Garrido, José Luis, El Privilegio Rodado de los Reyes Católicos a Cádiz en 1493, Fundación Municipal de Cultura, Cádiz, 1992.

Martín GutiÉrRez, Emilio, "El Estrecho de Gibraltar en el siglo XIV: Redes comerciales en Algeciras", Revista del Centro de Estudios Históricos de Granada y su Reino, 30 (2018), pp. 51-69.

Medrano Fernández, Violeta, Un mercado entre fronteras: Las relaciones comerciales entre Castilla y Portugal al final de la Edad Media, Universidad de Valladolid, Salamanca, 2010.

Mosquera Merino, María del Carmen, La Señoría de Ceuta en el siglo XIII (Historia política y económica), Instituto de Estudios Ceutíes, Ceuta, 1994.

MuÑoz GómEz, Víctor, "Puertos, abras, cabos e islas: la topografía medieval de la costa atlántica de Andalucía a través de las cartas portulanas (Ss. XIV-XVI)", De mar a mar: Los puertos castellanos en la Baja Edad Media, Eduardo Aznar Vallejo y Roberto José González Zalacain (coords.), Servicio de Publicaciones Universidad de La Laguna, San Cristóbal de La Laguna, 2015, pp. 179-211.

NAM, Jong-Kuk, Le commerce du coton en Méditerranée à la fin du Moyen Age, BRILL, Boston-Leyden, 2007.

NiColin, Angelo, "Commercio marittimo genovese in Inghilterra nel Medioevo (12801495)", Atti della Società Ligure di Storia Patria, vol. 121, 1 (2007), pp. 215-328.

Ortega Villoslada, Antonio, "La coca en el intercambio mercante Atlántico-Mediterráneo", Anuario de Estudios Medievales, no 38/1(2008), pp. 429-444. 
Ortega Villoslada, Antonio, El Reino de Mallorca y el mundo atlántico (1230-1349), Ed. Netbiblo-UNED, Oleiros (La Coruña), 2010.

Ortega Villoslada, Antonio, "Mallorca y el comercio atlántico. Siglos XIII-XIV", Memòries de la Reail Acadèmia Mallorquina d'Estudis Genealògics, Heràldics $i$ Històrics, 20 (2010), pp. 61-80.

Ortega Villoslada, Antonio, La marina mercante medieval y la Casa de Mallorca: entre el Mediterráneo y el Atlántico, Pagès editors, Lleida, 2015.

Отте, Enrique, Sevilla y sus mercaderes a fines de la Edad Media, Antonio Miguel Bernal y Antonio Collantes de Terán Sánchez (eds.), Fundación El Monte, Sevilla, 1996.

OuErfelli, Mohamed, Le sucre: Production, commercialisation et usages dans la Méditerranée médiévale, BRILL, Boston-Leyden, 2007.

Pardessus, Jean Marie, Collection des lois maritimes antérieures au XVIII siècle, París, 1834, vol. III.

PÉREZ-EmBID, Fernando, “Las escalas ibéricas del Mediterráneo al Mar del Norte", Les grandes escales. Recueils de la Société Jean Bodin pour l'Historie comparartive des institutions, XXXII (1972), pp. 265-290.

Petti BAlBi, Giovanna, "Un binomio indisoluble: navegación comercial y armamento público en Génova en los siglos XIV-XV", Navegación institucional y navegación privada en el Mediterráneo medieval, Raúl González Arévalo (ed.), Alhulia, Granada, 2016, pp. 41-76.

PICARD, Christophe, La Mer des Califes: Une historie de la Méditerranée musulmane, Editorial Seuil, París, 2015.

RenOUARD, Yves, reseña del libro Les relations commerciales entre Gênes, la Belgique et l'Outremont, d'après les Archives notariales génoises, aux XIIIe et XIVe siècles de Renée Doehaerd, Bulletin hispanique, tomo 49, no 3-4 (1947), pp. 464-467.

RozAs EsPañol, Ángel, "La ruta atlántica (siglos XIII-XIV): análisis de la formación de una ruta comercial", Espacio, Tiempo y Forma, Serie III Historia Medieval, 30 (2017), pp. 485-504.

Ruiz Pilares, Enrique y Bochaca, Michel, "Un exemple de relations commerciales entre le pays de Léon et l'Andalousie au début du XVI ${ }^{\mathrm{e}}$ siècle, d'après le compte d'un marchand de Morlaix", Annales de Bretagne et des Pays de l'Ouest, tome 123, nº 4 (2016), pp. 7-34 Rumeu de Armas, Antonio, Cádiz, metrópoli del comercio con África en los siglos XV y XVI, Caja de Ahorros Cádiz, Cádiz, 1976.

SAlicrú i Lluch, Roser “Génova y Castilla, genoveses y Granada. Política y comercio en el Mediterráneo occidental en la primera mitad del siglo XV (1431-1439)", El sultanato nazarí de Granada, Génova y la Corona de Aragón en el siglo XV, Universidad de Granada, Granada, 2007, pp. 17-112.

SÁnchez Herrero, José, Cádiz. La ciudad medieval y cristiana (1260-1525), Publicaciones del Monte de Piedad-Caja de Ahorros, Córdoba, 1986. 
SÁnchez SAus, Rafael, "Cádiz en la época medieval”, Historia de Cádiz, Editorial Sílex, Madrid, 2005, pp. 146-281.

Simbula, Pinuccia F., "Apertura de las rutas comerciales de las flotas italianas hacia el Atlántico", Navegación marítima del Mediterráneo al Atlántico, Antonio Malpica Cuello (ed.), THARG, Granada, 2001, pp. 207-258.

STÖCKLY, Doris, Le système de l'Incanto des galées du marché à Venise, fin XIII - milieu $X V^{e}$ siècle, BRILL, Boston-Leyden, 1995.

VAquero PiÑeiro, Manuel, "Relaciones entre las villas cántabras de la costa y la Península Italiana en los siglos XIV y XV. Datos para su estudio", El Fuero de Santander y su época. Actas del Congreso conmemorativo de su VIII Centenario, DiputaciónAyuntamiento-Universidad, Santander, 1989, pp. 305-315.

VAquero PiÑEIro, Manuel, "Naves vascas en el puerto de Civitavecchia en la Baja Edad Media”, Letras de Deusto, 36, 110 (2006), pp. 207-234. 
